\title{
Correction: HDAC7 is an actionable driver of therapeutic antibody resistance by macrophages from CLL patients
}

\author{
M. Burgess - Y. C. E. Chen - S. Mapp - A. Blumenthal - P. Mollee - D. Gill • N. A. Saunders
}

Published online: 22 December 2020

(c) The Author(s), under exclusive licence to Springer Nature Limited 2020

\section{Correction to: Oncogene}

https://doi.org/10.1038/s41388-020-01394-w
Since publication of the article the authors realised one of the author names was incorrect. Y.C.E. Chen was incorrectly written as U.C.E. Chen. This has now been corrected in the PDF and XML. 